\title{
Determinants of early initiation of breastfeeding in rural Tanzania
}

\author{
Amon Exavery ${ }^{1 *}$, Almamy Malick Kanté ${ }^{1,2}$, Ahmed Hingora $^{1}$ and James F. Phillips ${ }^{2}$
}

\begin{abstract}
Background: Breastfeeding is widely known for its imperative contribution in improving maternal and newborn health outcomes. However, evidence regarding timing of initiation of breastfeeding is limited in Tanzania. This study examines the extent of and factors associated with early initiation of breastfeeding in three rural districts of Tanzania.

Methods: Data were collected in 2011 in a cross-sectional survey of random households in Rufiji, Kilombero and Ulanga districts of Tanzania. From the survey, 889 women who had given birth within 2 years preceding the survey were analyzed. Both descriptive and inferential statistical analyses were conducted. Associations between the outcome variable and each of the independent variables were tested using chi-square. Logistic regression was used for multivariate analysis.
\end{abstract}

Results: Early initiation of breastfeeding (i.e. breastfeeding initiation within $1 \mathrm{~h}$ of birth) stood at $51 \%$. The odds of early initiation of breastfeeding was significantly $78 \%$ lower following childbirth by caesarean section than vaginal birth (adjusted odds ratio $(\mathrm{OR})=0.22 ; 95 \%$ confidence interval $(\mathrm{Cl}) 0.14,0.36)$. However, this was almost twice as high for women who gave birth in health facilities as for those who gave birth at home $(\mathrm{OR}=1.75 ; 95 \% \mathrm{Cl} 1.25$, 2.45). Furthermore, maternal knowledge of newborn danger signs was negatively associated with early initiation of breastfeeding (moderate vs. high: $\mathrm{OR}=1.73 ; 95 \% \mathrm{Cl} 1.23,2.42$; low vs. high: $\mathrm{OR}=2.06 ; 95 \% \mathrm{Cl} 1.43,2.96$ ). The study found also that early initiation of breastfeeding was less likely in Rufiji compared to Kilombero $(\mathrm{OR}=0.52 ; 95 \% \mathrm{Cl}$ $0.31,0.89)$, as well as among ever married than currently married women $(\mathrm{OR}=0.46 ; 95 \% \mathrm{Cl} 0.25,0.87)$.

Conclusions: To enhance early initiation of breastfeeding, using health facilities for childbirth must be emphasized and facilitated among women in rural Tanzania. Further, interventions to promote and enforce early initiation of breastfeeding should be devised especially for caesarean births. Women residing in rural locations and women who are not currently married should be specifically targeted with interventions aimed at enhancing early initiation of breastfeeding to ensure healthy outcomes for newborns.

Keywords: Breastfeeding, Timely initiation, Early initiation, Prevalence, Predictors, Rufiji, Kilobero, Ulanga, Tanzania

\section{Background}

To ensure the health of newborns, the World Health Organization (WHO) recommends placing newborn babies in direct contact with their mothers immediately after birth for at least $1 \mathrm{~h}$, and encouraging initiation of breastfeeding as soon as possible [1]. Evidence shows that if newborns are exposed to breastfeeding at this early stage, they are much more likely to adhere to exclusive breastfeeding and ultimately have better health

\footnotetext{
* Correspondence: aexavery@ihi.or.tz

${ }^{1}$ Ifakara Health Institute, Plot 463, Kiko Avenue, P.O. Box 78373, Mikocheni, Dar es Salaam, Tanzania

Full list of author information is available at the end of the article
}

outcomes [2, 3]. Exclusive breastfeeding contributes to a $22 \%$ reduction in neonatal mortality [4], suggesting that the earlier breastfeeding initiation takes place, the lower the chances of neonatal mortality, mostly due to reduction in infection [5]. A recent systematic review regarding timing of breastfeeding initiation shows that initiating breastfeeding within $1 \mathrm{~h}$ of birth results in significant reduction of the risk of neonatal mortality [6]. One ecological study that uses demographic and health survey (DHS) data from 67 countries shows a protective effect of breastfeeding within the first hour of birth on neonatal survival [7]. 
Several other studies indicate similar results regarding the importance of early initiation of breastfeeding $[4,8]$.

The benefits of early initiation of breastfeeding extend to both the mother and the newborn. Consistent production and ejection of breast milk is facilitated by secretion of prolactin and oxytocin which are stimulated by suction of the nipple by the newborn, thus indicating that early initiation of breastfeeding aids in consistent breastfeeding. The first breast milk to be secreted for the first few days after birth, known as colostrum, provides the newborn with natural immunity from the mother to avert infections. Therefore, it is particularly important to the health of newborns that they are breastfed immediately after birth [9]. Breast milk has immunological properties which protect newborn babies against common illnesses and infectious diseases such as diarrhea [10, 11], respiratory infections especially pneumonia [12], meningitis $[10,11]$ and neonatal sepsis [13-16], all of which are important causes of infant morbidity and mortality.

In addition to these benefits, early suckling stimulates the contraction of the uterus after childbirth which reduces risk of postpartum hemorrhage [9]. Furthermore, breastfeeding lengthens the postpartum infertility period, helps the mother return to her pregestational weight, and reduces the risk of breast cancer [17] as well as ovarian cancer [18-20].

While the benefits of early initiation of breastfeeding are well recognized, a significant proportion of newborn babies in many countries are still not breastfed within $1 \mathrm{~h}$ of birth as the WHO recommends. This implies that barriers still exist, thus necessitating further investigations. In Tanzania, the recent DHS report shows that less than a half $(49 \%)$ of newborn babies are breastfed within $1 \mathrm{~h}$ of birth, and ranges from $18 \%$ in Rukwa region to $93 \%$ in Manyara region [9]. However, $94 \%$ of the Tanzanian newborns are breastfed within 1 day after birth [9]. In the Sub-Saharan African region, prevalence of early initiation of breastfeeding varies widely, with less than $60 \%$ of mothers in Kenya [21], Ethiopia [22] and Lesotho [23] initiating breastfeeding within the first hour; and as many as $95 \%$ of women in Malawi adhering to this recommendation [24]. Elsewhere, early initiation of breastfeeding has been estimated at $11 \%$ in one province in Saudi Arabia [25], $31 \%$ in India [26] and $83 \%$ in Sri Lanka [27].

Several factors associated with early initiation of breastfeeding have been identified. This includes absence of prelacteal feeding, rural residence, absence of breast problems, and multi-parity [25]. One recent systematic review found that childbirth by caesarean section is the most consistent risk factor for delayed breastfeeding initiation [8]. Other factors identified by this review were low family income, maternal age under 25 years, low maternal education, absence of prenatal health visits, home birth, absence of prenatal guidance on breastfeeding, and preterm birth. In Sri Lanka, delayed initiation of breastfeeding was associated with low birth weight and childbirth by caesarean section, but less likely among female infants and mothers within higher wealth quintiles [27]. Furthermore, one study in India found that the practice is influenced by educational level, economic status, mother's tribe, place of birth, prenatal visits to health care facilities, assistance during childbirth, and partner's violent behavior [26]. Unfortunately, Tanzaniaspecific literature on timing of initial breastfeeding is scarce. One large cross-sectional survey was conducted in Southern Tanzania regarding newborn care practices that reported prevalence of breastfeeding initiation within $1 \mathrm{~h}$, yet this study did not assess factors associated with the behavior [28]. Only the recent DHS report for Tanzania points out that early initiation of breastfeeding increases with maternal educational status, wealth quintile, urban residence, and professional or skilled birth attendance [9]. Given that the proportion of women who breastfeed their newborns within $1 \mathrm{~h}$ of birth varies widely across Tanzania [9], and the lack of district level data on this behavior, it is possible that factors underlying the behaviour differ by geographical locations due to differences in context specific conditions. Therefore the current analysis assesses the levels and factors associated with early initiation of breastfeeding among women who have recently given birth in Rufiji, Kilombero, and Ulanga districts of Tanzania.

\section{Methods}

\section{Study area}

Data for this study were collected in three rural and impoverished districts of Rufiji, Kilombero and Ulanga in Tanzania using health and demographic surveillance system (HDSS) platforms of Rufiji [29] and Ifakara [30]. The Rufiji HDSS is located in the Rufiji district of the Pwani region, while the Ifakara HDSS sits on geographical portions of both Kilombero and Ulanga districts in Morogoro region. A HDSS is a longitudinal, health and vital events registration system that monitors demographic events, such as births, deaths, and migrations in a geographically defined setting of individuals. During the survey in 2011, these HDSS were following up a combined population of about 370,000 people.

\section{Study design, sampling and study participants}

This study is cross-sectional in design. It is based on a household survey which was carried out in 2011 in the study area to cater for baseline needs of the Connect Project $[31,32]$. The project tests a child survival impact and health behavior change of adding paid community health workers known as community health agents (CHAs) to an existing facility focused health system. This is happening 
in Rufiji, Kilombero and Ulanga districts of Tanzania. A sampling frame of households was obtained from the HDSS and probability proportionate to size (PPS) technique was used to select the sample. This ensured sample representativeness because the villages varied remarkably in terms of their population sizes. During the survey, a total of 2183 households were successfully visited. These households produced 3127 women who were interviewed, out of which 889 were eligible, hence selected for the current analysis. More details about the survey are available elsewhere [32].

\section{Variables}

This study assessed one binary outcome variable, namely, early initiation of breastfeeding. According to WHO, early initiation of breastfeeding means providing mother's breast milk to infants within $1 \mathrm{~h}$ of birth [33]. The variable had two categories, "yes" and "no", which were assigned codes of " 1 " and " 0 " respectively for computational purposes. This variable was derived from the original fielded question which stated "how long after birth did you first put (name of the child) to the breast?" Responses to this question were depicted in number of hours, except that if the child was breastfed within $1 \mathrm{~h}$ of birth it was recorded as zero. At last, the outcome variable took the following form:

\section{Early initiation of breastfeeding}

$=\left\{\begin{array}{c}1 \text { if breastfeeding was initiated within one hour of birth } \\ 0 \text { if breastfeeding began on or after the first hour of birth }\end{array}\right.$

Several independent variables were assessed. This included maternal age (in years), marital status, education attained, ethnic group, religion, household socioeconomic status which was constructed using principal component analysis (PCA) of household assets [34], district of residence, type of residence, gravidity, and pregnancy wantedness. Others were mode of childbirth, place of birth, number of times a woman received antenatal care (ANC) during pregnancy, whether or not during pregnancy a woman was counseled on immediate breastfeeding after birth, mother's knowledge of health practices related to pregnancy, and mother's knowledge of newborn danger signs.

The variable depicting mother's knowledge of health practices related to pregnancy was constructed from seven questions which asked whether or not during pregnancy a woman was counseled on: (a) financial preparation for childbirth (b) Breastfeeding immediately after birth (c) Danger signs during childbirth (d) Using a skilled birth attendant (e) Family planning (f) Identifying emergency transport options and (g) Danger signs of pregnancy. A "yes" response to each of these questions was given a score of " 1 ", and a score of " 0 " if the response was "no". Total number of the services for which the mother received counseling about was calculated for each woman, with possible values ranging from zero if none of the services was received to seven if all services were received. Finally three categories were constructed from the values, such that all women who scored seven were grouped together and defined as of comprehensive knowledge of health practices related to pregnancy. Women who scored between three and six inclusive were considered as having moderate knowledge, and those who had less than three scores were considered as having low knowledge of health practices related to pregnancy. This approach was similarly applied in the construction of the mother's knowledge of newborn danger signs variable. Each woman was asked to mention any danger signs or symptoms which show that after birth a newborn baby needs health care. Reported danger signs were: (a) Fever (b) Unable to suckle/ feed (c) Difficult/fast breathing (d) Diarrhea (e) Convulsions (f) Persistent vomiting (g) Yellow palms/soles/ eyes/jaundice (h) Lethargy (i) Red/discharging eyes (j) Skin pustules (k) Skin around cord red (l) Pus from cord (m) Failure to pass urine (n) Shivering/cold baby/low temperature (o) Bluish palms and soles (p) Very small baby/below normal weight and (q) Others. Women who reported at least three of these danger signs were defined as having high knowledge of newborn danger signs. Women with moderate knowledge of newborn danger signs referred to those who reported only two danger signs, and those who reported less than two danger signs were defined as having low knowledge.

\section{Statistical analysis}

Data analysis was both descriptive and inferential, and was carried out using STATA statistical software (version 11). Frequencies were calculated in one-way tabulations to reveal distributional features of the data across each variable. Bivariate analysis was then conducted by crosstabulating early initiation of breastfeeding against each of the independent variables. In this process, the degree of association between each pair of cross-tabulated variables was tested using chi-square test $(\chi 2)$ because all variables involved in the analysis were categorical. Logistic regression was used to perform multivariate analysis (regression model with more than one independent variable) in order to identify independent factors associated with early initiation of breastfeeding. Using log-likelihood ratio test, a variable was selected for inclusion in the multivariate model if it was statistically significant at $5 \%$ level that its presence improved the overall model [35]. The model was also checked for statistical interactions and adequacy. Adequacy was checked using the Hosmer-Lemeshow goodness-of-fit test [35]. Adjusted 
odds ratios (OR) and their corresponding $95 \%$ confidence intervals (CIs) and $p$-values were presented.

\section{Ethical consideration}

A survey which produced these data received an ethical approval from both the Medical Research Coordinating Committee (MRCC) of the National Institute for Medical Research (NIMR) (NIMR/HQ/R.8a/Vol.IX/1203) and the Ifakara Health Institute's Institutional Review Board (IRB) (IHI/IRB/No. 16-2010) in Tanzania. Ethical approval was also granted by the IRB of Columbia University, USA (Protocol AAAF3452). All respondents participated in the survey voluntarily, and signed an informed consent form prior to being interviewed. Completed questionnaires and consent forms were stored separately to ensure anonymity of the data.

\section{Results}

\section{Profile of respondents}

As Table 1 shows, the 889 women who were analyzed had an average age of $27.8( \pm 7.6)$ years. A majority of them $(79.9 \%)$ were married. In terms of education, $25 \%$ had never been to school, $70.3 \%$ had primary education, and only $4.7 \%$ had secondary education or higher. Kilombero district represented more than half (58.5\%) of the respondents, while Rufiji and Ulanga had 24.9 and $16.7 \%$ of the respondents respectively. The majority $(81.1 \%)$ of the respondents resided in rural settings. Of all these women, $12.9 \%$ gave birth by caesarean section and the rest vaginally.

\section{Early initiation of breastfeeding by background characteristics}

Overall, $51 \%$ of the respondents initiated breastfeeding of their newborn babies within $1 \mathrm{~h}$ of birth as recommended by the WHO. By the end of the first day following childbirth, $94 \%$ of the women had already initiated breastfeeding (Fig. 1). The proportion of women initiating breastfeeding within $1 \mathrm{~h}$ varied significantly by some characteristics of the respondents. The most important factor was mode of childbirth, whereby early initiation of breastfeeding became $54.4 \%$ among women who gave birth vaginally, and $27.8 \%$ among women who gave birth by caesarean section $(p<0.001)$. Also early initiation of breastfeeding was significantly higher among women who gave birth in health facilities than those who gave birth at home (53.9 \% against $42.3 \%$ ). Mother's knowledge of newborn danger signs was a significant variable in an opposite direction, such that early initiation of breastfeeding was lowest at $43.1 \%$ among women with high knowledge and highest at $57.5 \%$ among women with low knowledge of newborn danger signs.
Furthermore, ethnicity was also associated with early initiation of breastfeeding, whereby the lowest proportion was observed among Sukuma women (31.4\%) and the highest among Pogoro women (59.1\%). Similarly, religion was also significant, with early initiation of breastfeeding being $53.5 \%$ among Muslim women, $51.7 \%$ among Christian women and $29.3 \%$ among women with traditional or other unspecified religions $(p=0.002)$. Other variables showed no significant association with early initiation of breastfeeding (Table 2).

\section{Correlates of early initiation of breastfeeding}

As show in Table 3, mode of childbirth was the strongest independent determinant of early initiation of breastfeeding, whereby women who gave birth by caesarean section were $78 \%$ less likely compared to women who gave birth vaginally to initiate breastfeeding within $1 \mathrm{~h}$ of birth (adjusted odds ratio $(\mathrm{OR})=0.22,95 \%$ confidence interval (CI) 0.14, 0.36). Place of childbirth was the other key determinant, with women who gave birth in health facilities being almost twice as likely as women who gave birth at home to initiate breastfeeding within $1 \mathrm{~h}$ of birth (OR $=1.75,95 \%$ CI 1.25, 2.45). Furthermore, ever married women (currently divorced or widowed) were significantly $54 \%$ less likely to initiate breastfeeding within $1 \mathrm{~h}$ compared to married women $(\mathrm{OR}=0.46,95 \% \mathrm{CI} 0.25,0.87)$. There was also an issue with district of residence, whereby women in Rufiji district were significantly $48 \%$ less likely than women in Kilombero district to initiate breastfeeding in $1 \mathrm{~h}$ of birth $(\mathrm{OR}=0.52,95 \%$ CI 0.31, 0.89). Surprisingly, the lower the mother's knowledge of newborn danger signs, the higher the odds of early initiation of breastfeeding (moderate knowledge: $\mathrm{OR}=1.73,95 \%$ CI 1.23, 2.42; low knowledge: OR $=2.06,95 \%$ CI 1.43, 2.96).

Women with formal education at secondary or higher levels were almost twice as likely as those without to initiate breastfeeding within $1 \mathrm{~h}$, but the effect was not significant at $5 \%(\mathrm{OR}=1.94,95 \% \mathrm{CI} 0.89,4.25)$. Insignificant also were ethnicity, religion, type of residence, and pregnancy wantedness. Early initiation of breastfeeding was also not affected by knowledge of immediate breastfeeding, number of ANC visits and mothers knowledge of health related practices during pregnancy.

\section{Discussion}

This study assessed prevalence and determinants of early initiation of breastfeeding among 889 women who had recently given birth in Kilombero, Rufiji and Ulanga districts of Tanzania, using cross-sectional household survey data collected in 2011. As highlighted previously, early initiation of breastfeeding is an essential component of maternal and newborn health. Early suckling stimulates the production of breast milk as well as 
Table 1 Background characteristics of respondents analyzed for timing of breastfeeding initiation in rural Tanzania $(n=889)$

\begin{tabular}{|c|c|c|}
\hline & $\begin{array}{l}\text { Absolute number } \\
\text { of respondents (n) }\end{array}$ & Percent (\%) \\
\hline Overall & 889 & 100.0 \\
\hline \multicolumn{3}{|l|}{ Maternal age (years) } \\
\hline$<20$ & 132 & 14.9 \\
\hline $20-34$ & 548 & 61.6 \\
\hline$>34$ & 209 & 23.5 \\
\hline Mean $=27.8, \operatorname{Min}=15, \operatorname{Max}=51$ & - & - \\
\hline \multicolumn{3}{|l|}{ Marital status } \\
\hline Married & 710 & 79.9 \\
\hline Ever married & 49 & 5.5 \\
\hline Single & 130 & 14.6 \\
\hline \multicolumn{3}{|l|}{ Education attained } \\
\hline None & 222 & 25.0 \\
\hline Primary & 625 & 70.3 \\
\hline Secondary+ & 42 & 4.7 \\
\hline \multicolumn{3}{|l|}{ Ethnic group } \\
\hline Ndengereko & 137 & 15.4 \\
\hline Ngindo & 126 & 14.2 \\
\hline Pogoro & 127 & 14.3 \\
\hline Sukuma & 102 & 11.5 \\
\hline Other & 397 & 44.7 \\
\hline \multicolumn{3}{|l|}{ Religion } \\
\hline Muslim & 452 & 50.8 \\
\hline Christian & 379 & 42.6 \\
\hline Traditional/other & 58 & 6.5 \\
\hline \multicolumn{3}{|l|}{ Socioeconomic status } \\
\hline Poor & 405 & 45.6 \\
\hline Middle & 284 & 32.0 \\
\hline Rich & 200 & 22.5 \\
\hline \multicolumn{3}{|l|}{ District of residence } \\
\hline Kilombero & 520 & 58.5 \\
\hline Rufiji & 221 & 24.9 \\
\hline Ulanga & 148 & 16.7 \\
\hline \multicolumn{3}{|l|}{ Type of residence } \\
\hline Township/suburban & 168 & 18.9 \\
\hline Rural & 721 & 81.1 \\
\hline \multicolumn{3}{|l|}{ Pregnancy wantedness } \\
\hline Intended & 456 & 51.3 \\
\hline Mistimed & 299 & 33.6 \\
\hline Unwanted & 134 & 15.1 \\
\hline \multicolumn{3}{|l|}{ Mode of childbirth } \\
\hline Vaginal & 774 & 87.1 \\
\hline
\end{tabular}

Table 1 Background characteristics of respondents analyzed for timing of breastfeeding initiation in rural Tanzania $(n=889)$ (Continued)

\begin{tabular}{lll}
\hline Caesarean section & 115 & 12.9 \\
Place of childbirth & & \\
Home & 227 & 25.5 \\
Health facility & 662 & 74.5 \\
\hline
\end{tabular}

oxytocin which helps the uterus to contract and reduces postpartum blood loss. Colostrum, which is contained in the first breast milk is highly nutritious and has antibodies which protect the newborn baby from acquiring diseases. Moreover, early initiation of breastfeeding enhances bonding between the mother and the child. Therefore early breastfeeding initiation is very crucial for the health of the newborn baby as well as the mother.

Findings from this study reveal that slightly more than one half (51\%) of the women who had given birth within 2 years preceding the survey in the study area initiated breastfeeding within $1 \mathrm{~h}$ of birth. This shows presence of a significant proportion of newborn babies in the study area who are not breastfed within $1 \mathrm{~h}$ of birth as recommended, and could partly be linked with misconceptions about early breastfeeding as similarly noted in southern Tanzania, that colostrum is dirty and should thus not be given to newborn babies [36]. The observed proportion of early initiation of breastfeeding by this study is comparable to that found in a rural area of Morogoro region in Tanzania [37] as well as the national estimate of $49 \%$ [9], but significantly higher than $18 \%$ reported in southern Tanzania [28]. Early initiation of breastfeeding within Tanzania has been reported to vary between rural and urban areas (45 and $62 \%$ respectively), and ranges from $18 \%$ in Rukwa to $93 \%$ in Manyara region [9]. Outside Tanzania, our observation is comparable to 52 and $53 \%$ observed in Ethiopia [22] and Lesotho [23] respectively, but lower than $58 \%$ observed in Kenya [21] and even lower compared to $95 \%$ recorded in Malawi in 2010 [24].

In the multivariate analysis, childbirth by caesarean section emerged as the strongest factor with negative association with early initiation of breastfeeding. It has been pointed out that postoperative care sometimes takes longer, preventing the mother from achieving contacting her baby during the postpartum period, thus delaying breastfeeding initiation [38]. This association between childbirth by caesarean section and delayed breastfeeding initiation is consistent with a recent systematic review [8] as well as other studies [39-42]. In many low and middle income countries, rates of childbirth by caesarean section are rapidly growing [43]. In Tanzania for example, the current rate of childbirth by 


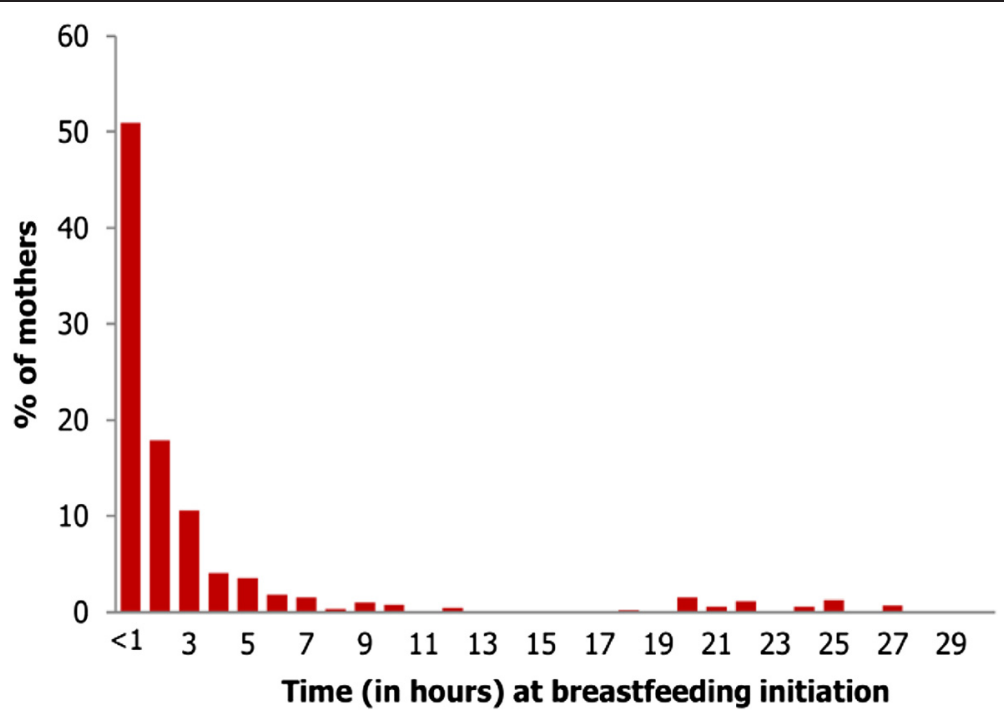

Fig. 1 Percentage distribution of 889 women who have recently given birth in three rural districts of Tanzania according to the time elapsed after childbirth at which they initiated breastfeeding of their newborns babies

caesarean section stands at $5 \%$ [9] and it is $13 \%$ in the current study area from these data. While caesarean section is considered a valuable lifesaving tool for both the mother and newborn in an obstetric emergency [44], interventions that can enhance early initiation of breastfeeding following caesarean section are greatly needed, as well as reducing or if possible stopping caesarean sections that have no medical indication [43]. This is because a caesarean section in one pregnancy suggests the same or at least specialized medical care in subsequent childbirth in order to minimize the risk of complications such as uterus rupture due to the scar from previous caesarean (s). Unfortunately, the fragile health system in the country as the case in many less developed countries may not adequately support this when it is massively needed.

With respect to place of childbirth, women who gave birth in health facilities were more likely than those who gave birth at home to initiate breastfeeding within $1 \mathrm{~h}$ of birth. This may be because health workers at health facilities facilitate timely initiation of breastfeeding. This implies that efforts to discourage nonuse of health facilities for childbirth should continue given the detrimental health outcomes associated with the practice, including delayed breastfeeding initiation which consequently increases the risk of newborn morbidity and mortality $[8,26]$. Timely initiation of breastfeeding should as well be encouraged for babies born at home. In communities with community health workers (CHWs), which is the case with CHAs in the study area [31], this may be addressed during regular household visits whereby pregnant women can be identified and provided with basic health care and promotion of maternal and newborn health practices.
Maternal knowledge of newborn danger signs was negatively associated with early initiation of breastfeeding, and this observation came up in a dose-response fashion. This was unexpected, as it was anticipated that higher knowledge would increase the likelihood that breastfeeding would be initiated within $1 \mathrm{~h}$ of birth. While previous scholars have found that higher educational attainment (not knowledge of newborn danger signs) was associated with higher likelihood of early initiation of breastfeeding $[8,9,26]$, the effect of knowledge of newborn danger signs on early initiation of breastfeeding is missing in the previous literature. However, a somewhat similar study in Ghana found that maternal knowledge of at least four newborn danger signs is associated with good neonatal feeding [45]. Ultimately, this study was unable to ascertain the mechanisms fostering this observation, thus warranting further research, especially qualitative studies.

Variations in early initiation of breastfeeding existed between districts, with women in Rufiji district being less likely than those in Kilombero district to initiate breastfeeding early. Women in Ulanga district were similar to those in Kilombero district, possibly because these two districts are in the same geographical location and share a border, thus women therein share the same environment, a situation which may shape their behaviors and health practices alike. Rufiji district, however, is located far from Ulanga and Kilombero, suggesting that variations in environments, cultural values, beliefs, and practices may account for the differences in breastfeeding practice. Although specific explanations of the observed finding are lacking, it has been noted that early initiation of breastfeeding in Tanzania vary by geographical locations [9]. 
Table 2 Breastfeeding initiation within 1 h of birth by each independent variable $(n=889)$

\begin{tabular}{llll}
\hline & $\begin{array}{l}\text { Absolute } \\
\text { number of } \\
\text { respondents }(n)\end{array}$ & $\begin{array}{l}\text { \% of women } \\
\text { breastfed their } \\
\text { newborns within } \\
1 \text { h of birth }\end{array}$ & $p$-value \\
\hline OVERALL & 889 & 51.0 & -
\end{tabular}

Maternal age (years)

$\begin{array}{cccc}<20 & 132 & 54.6 & 0.494 \\ 20-34 & 548 & 49.5 & \\ >34+ & 209 & 52.6\end{array}$

Marital status

Married

0.212

Single

Education attained

$\begin{array}{ll}\text { None } & 222 \\ \text { Primary } & 625 \\ \text { Secondary+ } & 42\end{array}$

Ethnic group

Ndengereko
Ngindo
Pogoro
Sukuma
Other

Religion

$\begin{array}{ll}\text { Muslim } & 452 \\ \text { Christian } & 379 \\ \text { Traditional/other } & 58\end{array}$

Socioeconomic status

$\begin{array}{lll}\text { Poor } & 405 & 48.6 \\ \text { Middle } & 284 & 51.1 \\ \text { Rich } & 200 & 55.5\end{array}$

District of residence

$\begin{array}{lll}\text { Kilombero } & 520 & 53.9 \\ \text { Rufiji } & 221 & 48.4 \\ \text { Ulanga } & 148 & 44.6\end{array}$

Type of residence

Township/suburban

Rural

Pregnancy wantedness

$\begin{array}{lll}\text { Intended } & 456 & 49.8 \\ \text { Mistimed } & 299 & 48.8 \\ \text { Unwanted } & 134 & 59.7\end{array}$

Mode of childbirth

$\begin{array}{lll}\text { Vaginal } & 774 & 54.4 \\ \text { Caesarean section } & 115 & 27.8\end{array}$

Table 2 Breastfeeding initiation within 1 h of birth by each independent variable $(n=889)$ (Continued)

\begin{tabular}{|c|c|c|c|}
\hline \multicolumn{4}{|l|}{ Place of childbirth } \\
\hline Home & 227 & 42.3 & 0.002 \\
\hline Health facility & 662 & 53.9 & \\
\hline \multicolumn{4}{|l|}{ Gravidity } \\
\hline 1 & 181 & 55.8 & 0.325 \\
\hline $2-4$ & 422 & 50.2 & \\
\hline$>4$ & 286 & 49.0 & \\
\hline \multicolumn{4}{|c|}{$\begin{array}{l}\text { Number of ANC visits } \\
\text { made }\end{array}$} \\
\hline$<4$ & 507 & 52.1 & 0.444 \\
\hline$\geq 4$ & 382 & 49.5 & \\
\hline \multicolumn{4}{|c|}{$\begin{array}{l}\text { Counseled on immediate } \\
\text { breastfeeding during ANC } \\
\text { visits? }\end{array}$} \\
\hline No & 276 & 48.9 & 0.414 \\
\hline Yes & 613 & 51.9 & \\
\hline \multicolumn{4}{|c|}{$\begin{array}{l}\text { Mother's knowledge of } \\
\text { health practices related } \\
\text { to pregnancy }\end{array}$} \\
\hline Comprehensive & 310 & 54.5 & 0.210 \\
\hline Moderate & 359 & 50.4 & \\
\hline Low & 220 & 46.8 & \\
\hline \multicolumn{4}{|c|}{$\begin{array}{l}\text { Mother's knowledge of } \\
\text { newborn danger signs }\end{array}$} \\
\hline High & 325 & 43.1 & 0.001 \\
\hline Moderate & 310 & 53.9 & \\
\hline Low & 254 & 57.5 & \\
\hline
\end{tabular}

Differences in early initiation of breastfeeding also existed by marital status, with ever married women being less likely to initiate breastfeeding within $1 \mathrm{~h}$ than currently married women. Although this was independent of pregnancy wantedness, it remains unclear why this was the case. Further research, especially qualitative studies, are needed to further characterize differential breastfeeding practices and inform interventions to increase early initiation of breastfeeding.

\section{Limitations}

The retrospective nature of this study may have introduced recall bias which may consequently have affected the estimated prevalence of early initiation of breastfeeding in the study area. Also facility level variables such as status of health workers' training in babyfriendly hospital initiative (BFHI) were not available for inclusion. Furthermore, it is important to understand that cross-sectional designs limit causal inferences since they lack temporal information. The results of this 
Table 3 Multivariate logistic regression model of correlates of breastfeeding initiation within $1 \mathrm{~h}$ of birth in rural Tanzania in $2011(n=889)$

\begin{tabular}{|c|c|c|c|}
\hline Covariate & $\begin{array}{l}\text { Adjusted Odds } \\
\text { Ratio (OR) }\end{array}$ & $p$-value & $\begin{array}{l}95 \% \text { Confidence } \\
\text { Interval (Cl) }\end{array}$ \\
\hline \multicolumn{4}{|l|}{ Mode of childbirth } \\
\hline Vaginal (ref) & 1.00 & - & - \\
\hline Caesarean section & 0.22 & $<0.001$ & $0.14,0.36$ \\
\hline \multicolumn{4}{|l|}{ Place of childbirth } \\
\hline Home (ref) & 1.00 & - & - \\
\hline Health facility & 1.75 & 0.001 & $1.25,2.45$ \\
\hline \multicolumn{4}{|l|}{ Marital status } \\
\hline Married (ref) & 1.00 & - & - \\
\hline Ever married & 0.46 & 0.017 & $0.25,0.87$ \\
\hline Single & 0.83 & 0.384 & $0.54,1.26$ \\
\hline \multicolumn{4}{|l|}{ District of residence } \\
\hline Kilombero (ref) & 1.00 & - & - \\
\hline Rufiji & 0.52 & 0.016 & $0.31,0.89$ \\
\hline Ulanga & 0.83 & 0.414 & $0.52,1.31$ \\
\hline \multicolumn{4}{|c|}{$\begin{array}{l}\text { Mother's knowledge of } \\
\text { newborn danger signs }\end{array}$} \\
\hline High (ref) & 1.00 & - & - \\
\hline Moderate & 1.73 & 0.001 & $1.23,2.42$ \\
\hline Low & 2.06 & $<0.001$ & $1.43,2.96$ \\
\hline
\end{tabular}

Ref $=$ Reference category or baseline outcome. This model is adjusted for: education attained, pregnancy wantedness, religion, ethnicity, type of residence, whether or not a respondent was counseled on immediate breastfeeding during ANC visits, mother's knowledge of health practices related to pregnancy, and number of ANC visits made during pregnancy

study may not be generalizable nationally or beyond since the data was limited to three districts of Tanzania.

\section{Conclusions}

Despite the known health benefits of early initiation of breastfeeding to the mother and the newborn, only about half of the mothers in Rufiji, Kilombero, and Ulanga districts of Tanzania succeed in starting breastfeeding within $1 \mathrm{~h}$ of birth. Efforts should be taken to ensure the universality of this practice. Promotion of health facility use for childbirth should be continued and facilitated to enhance timely initiation of breastfeeding along with promoting other positive health outcomes. On the other hand, timely initiation of breastfeeding should be encouraged for babies born at home. Specifically, developing and implementing interventions to improve timely breastfeeding initiation following childbirth by caesarean section is of utmost importance. Further assessments should occur to understand why higher maternal knowledge of newborn danger signs decreases the odds of early initiation of breastfeeding. Ultimately, early initiation of breastfeeding should be promoted among Tanzanian mothers to ensure healthy outcomes for both mothers and newborns.

\section{Competing interests}

The authors declare that they have no competing interests.

\section{Authors' contributions}

Amon Exavery conceptualized the problem, performed data analysis and established the first draft of the manuscript. Almamy Malick Kanté contributed to data analysis as well as the write-up and critical review of the manuscript. Ahmed Hingora and James F, Fillips designed the primary study that produced these data and also critically read the current manuscript for intellectual inputs. All authors read and approved the final manuscript.

\section{Acknowledgements}

Data for this study were collected by the Ifakara Health Institute using a grant to Columbia University from the Doris Duke Charitable Foundation. Research assistants, field supervisors and communities as well as individual respondents are greatly acknowledged for making the survey a success. Anna Larsen from the Mailman School of Public Health of Columbia University is especially acknowledged for proofreading this manuscript.

\section{Author details}

${ }^{1}$ Ifakara Health Institute, Plot 463, Kiko Avenue, P.O. Box 78373, Mikocheni, Dar es Salaam, Tanzania. 'Department of Population and Family Health, Mailman School of Public Health, Columbia University, New York, USA.

Received: 8 May 2015 Accepted: 17 September 2015

Published online: 25 September 2015

\section{References}

1. World Health Organization, UNICEF: Baby-friendly hospital initiative: revised, updated and expanded for integrated care. Section 2. Strengthening and sustaining the baby-friendly hospital initiative: a course for decision-makers. WHO; 2009. http://apps.who.int/iris/bitstream/10665/43593/2/ 9789241594974_eng.pdf

2. World Health Organization: Evidence for the ten steps to successful breastfeeding. 1998.

3. Widström AM, Wahlberg V, Matthiesen AS, Eneroth P, Uvnäs-Moberg K, Werner $S$, et al. Short-term effects of early suckling and touch of the nipple on maternal behaviour. Early Hum Dev. 1990;21:153-63.

4. Edmond KM. Delayed breastfeeding initiation increases risk of neonatal mortality. Pediatrics. 2006;117:e380-6.

5. Edmond KM, Kirkwood BR, Amenga-Etego S, Owusu-Agyei S, Hurt LS. Effect of early infant feeding practices on infection-specific neonatal mortality: an investigation of the causal links with observational data from rural Ghana. Am J Clin Nutr. 2007:86:1126-31.

6. Khan J, Vesel L, Bahl R, Martines JC. Timing of breastfeeding initiation and exclusivity of breastfeeding during the first month of life: effects on neonatal mortality and morbidity- a systematic review and meta-analysis. Matern Child Health J. 2015;19:468-79.

7. Boccolini CS, de Carvalho ML, de Oliveira MIC, Pérez-Escamilla R. Breastfeeding during the first hour of life and neonatal mortality. J Pediatr (Rio J). 2013;89:131-6.

8. Esteves TMB, Daumas RP, Oliveira MI, Andrade CA, Leite IC. Factors associated to breastfeeding in the first hour of life: systematic review. Rev Saude Publica. 2014;48:697-708.

9. National Bureau of Statistics [Tanzania], ICF Macro. Tanzania Demographic and Health Survey 2010. Tanzania: NBS and ICF Macro; 2011.

10. Lamberti LM, Walker CLF, Noiman A, Victora C, Black RE. Breastfeeding and the risk for diarrhea morbidity and mortality. BMC Public Health. 2011;11:S15.

11. Bahl R, Frost C, Kirkwood BR, Edmond K, Martines J, Bhandari N, et al. Infant feeding patterns and risks of death and hospitalization in the first half of infancy: multicentre cohort study. Bull World Health Organ. 2005;83:418-26.

12. Lamberti LM, Zakarija-Grković I, Walker CLF, Theodoratou E, Nair H,

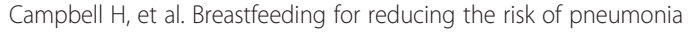
morbidity and mortality in children under two: a systematic literature review and meta-analysis. BMC Public Health. 2013;13:S18.

13. Ashraf RN, Jalil F, Zaman S, Karlberg J, Khan SR, Lindblad BS, et al. Breast feeding and protection against neonatal sepsis in a high risk population. Arch Dis Child. 1991;66:488-90.

14. Bhutta ZA, Yusuf K. Early-onset neonatal sepsis in Pakistan: a case control study of risk factors in a birth cohort. Am J Perinatol. 1997;14:577-81. 
15. Ashraf RN, Jalil F, Khan SR, Zaman S, Karlberg J, Lindblad BS, et al. Early child health in Lahore, Pakistan: V. Feeding patterns. Acta Paediatr Suppl. 1993;82 Suppl 390:47-61.

16. Victora C. Infection and disease: The impact of early weaning. Food Nutr Bull. 1996;17:390-6.

17. Collaborative Group on Hormonal Factors in Breast Cancer. Breast cancer and breastfeeding: collaborative reanalysis of individual data from 47 epidemiological studies in 30 countries, including 50302 women with breast cancer and 96973 women without the disease. Lancet. 2002;360:187-95.

18. Luan N-N, Wu Q-J, Gong T-T, Vogtmann E, Wang Y-L, Lin B. Breastfeeding and ovarian cancer risk: a meta-analysis of epidemiologic studies. Am J Clin Nutr. 2013;98:1020-31.

19. Toma TS, Rea MF. Benefícios da amamentação para a saúde da mulher e da criança: um ensaio sobre as evidências Benefits of breastfeeding for maternal and child health: an essay on the scientific evidence. Cad Saude Publica. 2008;24:S235-46.

20. Gwinn ML, Lee NC, Rhodes PH, Layde PM, Rubin GL. Pregnancy, breast feeding, and oral contraceptives and the risk of epithelial ovarian cancer. $J$ Clin Epidemiol. 1990;43:559-68.

21. Kenya National Bureau of Statistics (KNBS), ICF Macro. Kenya Demographic and Health Survey 2008-09. Kenya: KNBS and ICF Macro; 2010.

22. Central Statistical Agency [Ethiopia], ICF International. Ethiopia Demographic and Health Survey 2011. Ethiopia: Central Statistical Agency and ICF International; 2012

23. Ministry of Health and Social Welfare (MOHSW) [Lesotho], ICF Macro. Lesotho Demographic and Health Survey 2009. Lesotho: MOHSW and ICF Macro; 2010.

24. National Statistical Office (NSO), ICF Macro. Malawi Demographic and Health Survey 2010. Zomba, Malawi, and Calverton, Maryland, USA: NSO and ICF Macro; 2011

25. El-Gilany AH, Sarraf B, Al-Wehady A. Factors associated with timely initiation of breastfeeding in Al-Hassa province, Saudi Arabia. East Mediterr Health J. 2012;18:250-4

26. Sandor M, Dalal K. Influencing factors on time of breastfeeding initiation among a national representative sample of women in India. Health. 2013;5:2169-80.

27. Senarath U, Siriwardena I, Godakandage SSP, Jayawickrama H, Fernando DN Dibley MJ. Determinants of breastfeeding practices: An analysis of the Sri Lanka Demographic and Health Survey 2006-2007. Matern Child Nutr. 2012;8:315-29.

28. Penfold S, Hill Z, Mrisho M, Manzi F, Tanner M, Mshinda H, et al. A large cross-sectional community-based study of newborn care practices in southern Tanzania. PLoS One. 2010;5:e15593.

29. Rufiji Health and Demographic Surveillance Site, Tanzania. http:// www.indepth-network.org/Profiles/rufiji_hdss_2013.pdf.

30. Ifakara HDSS, Tanzania. http://www.indepth-network.org/Profiles/ Ifakara\%20HDSS.pdf.

31. Ramsey K, Hingora A, Kante M, Jackson E, Exavery A, Pemba S, et al. The Tanzania Connect Project: a cluster-randomized trial of the child survival impact of adding paid community health workers to an existing facilityfocused health system. BMC Health Serv Res. 2013;13:S6.

32. Exavery A, Kanté AM, Jackson E, Noronha J, Sikustahili G, Tani K, et al. Role of condom negotiation on condom use among women of reproductive age in three districts in Tanzania. BMC Public Health. 2012;12:1097.

33. WHO: Early initiation of breastfeeding. http://www.who.int/elena/titles/ early_breastfeeding/en/

34. Vyas S, Kumaranayake L. Constructing socio-economic status indices: how to use principal components analysis. Health Policy Plan. 2006;21:459-68.

35. Vittinghoff E, Shiboski SC, Glidden DV, McCulloch CE. Regression Methods in Biostatistics: Linear, Logistic, Survival, and Repeated Measures Models. New York: Springer Science + Business Media, Inc.; 2005.

36. Mrisho M, Schellenberg JA, Mushi AK, Obrist B, Mshinda H, Tanner M, et al. Understanding home-based neonatal care practice in rural southern Tanzania. Trans R Soc Trop Med Hyg. 2008;102:669-78.

37. Shirima R, Gebre-Medhin M, Greiner T. Information and socioeconomic factors associated with early breastfeeding practices in rural and urban Morogoro, Tanzania. Acta Paediatr. 2001;90:936-42.

38. Matthews MK. The relationship between maternal labour analgesia and delay in the initiation of breastfeeding in healthy neonates in the early neonatal period. Midwifery. 1989;5:3-10.
39. Pérez-Escamilla R, Maulén-Radovan I, Dewey KG. The association between cesarean delivery and breast-feeding outcomes among Mexican women. Am J Public Health. 1996;86:832-6.

40. Rowe-Murray HJ, Fisher JRW. Baby friendly hospital practices: cesarean section is a persistent barrier to early initiation of breastfeeding. Birth. 2002;29:124-31.

41. Victor R, Baines SK, Agho KE, Dibley MJ. Determinants of breastfeeding indicators among children less than 24 months of age in Tanzania: a secondary analysis of the 2010 Tanzania Demographic and Health Survey. BMJ Open. 2013;3:e001529.

42. Boccolini CS, de Carvalho ML, de Oliveira MIC, Vasconcellos AGG. Factors associated with breastfeeding in the first hour of life. Rev Saude Publica. 2011:45:69-78.

43. Kuyper E, Vitta B, Dewey K. Implications of cesarean delivery for breastfeeding outcomes and strategies to support breastfeeding. Alive Thrive Tech Brief. 2014;8:1-9.

44. Family Health International (Organization), Joseph L, Mailman School of Public Health, UNICEF, United Nations Population Fund, World Health Organization. Monitoring emergency obstetric care: a handbook. Geneva: World Health Organization; 2009.

45. Saaka M, Iddrisu M. Patterns and determinants of essential newborn care practices in rural areas of northern Ghana. Int J Popul Res. 2014;2014:e404387

\section{Submit your next manuscript to BioMed Central and take full advantage of:}

- Convenient online submission

- Thorough peer review

- No space constraints or color figure charges

- Immediate publication on acceptance

- Inclusion in PubMed, CAS, Scopus and Google Scholar

- Research which is freely available for redistribution 